\title{
Do You Know How Occupational Data for Health Can Support Quality Care?
}

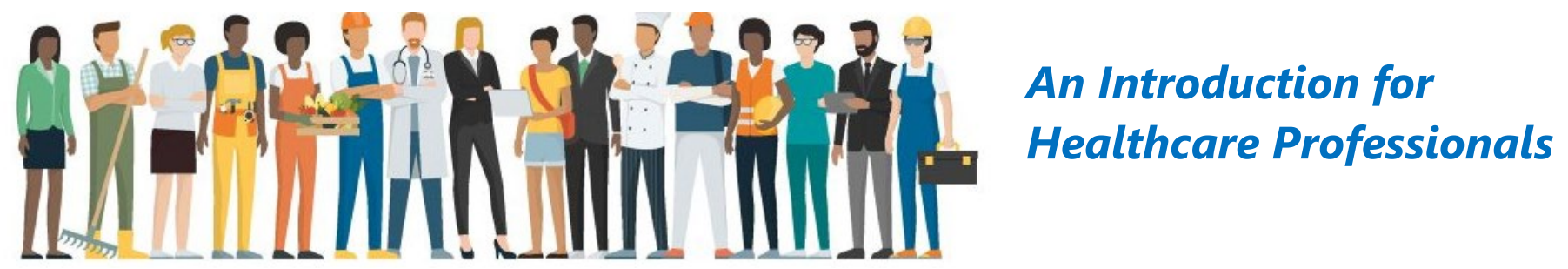

\section{What Is Occupational Data for Health (ODH)?}

- A method for your patients to report their standardized, useful work information to you.

- A customizable framework for your electronic health record (EHR) to meet the needs of your organization.

- A set of valuable information you can choose from, like employment status, jobs, usual (longest-held) work, voluntary work, retirement dates, and periods working in combat zones.

\section{Examples of How ODH Can Help You}

\section{Assist your patients who have chronic diseases}

- Identify night shift workers with poorly controlled diabetes and access educational materials.

\section{Improve preventive care for your high-risk populations of workers}

- Identify housepainters to inform them about the risks of lead paint exposure and the importance of blood level screening.

\section{Recognize new relationships between work and health in your patient populations}

- Identify trends or hotspots where infectious disease transmission might be occurring and inform public health authorities.

\section{Help your patients return to work after an illness or injury}

- Identify patients that operate heavy machinery or drive vehicles while at work and have been prescribed medications that can diminish alertness or response time to educate them about relevant restrictions.

Recognize your patients with work-related illnesses that require notification to a public health authority

- Identify pesticide poisoning in agricultural workers and inform public health authorities.

\section{Next Steps}

- Ask your patients about their work - it's where they spend one-third of their lives!

- Talk to your EHR vendor about incorporating ODH for your organization.

For more information, go to the NIOSH Electronic Health Records website or email us at EHRs and Work@CDC.gov.
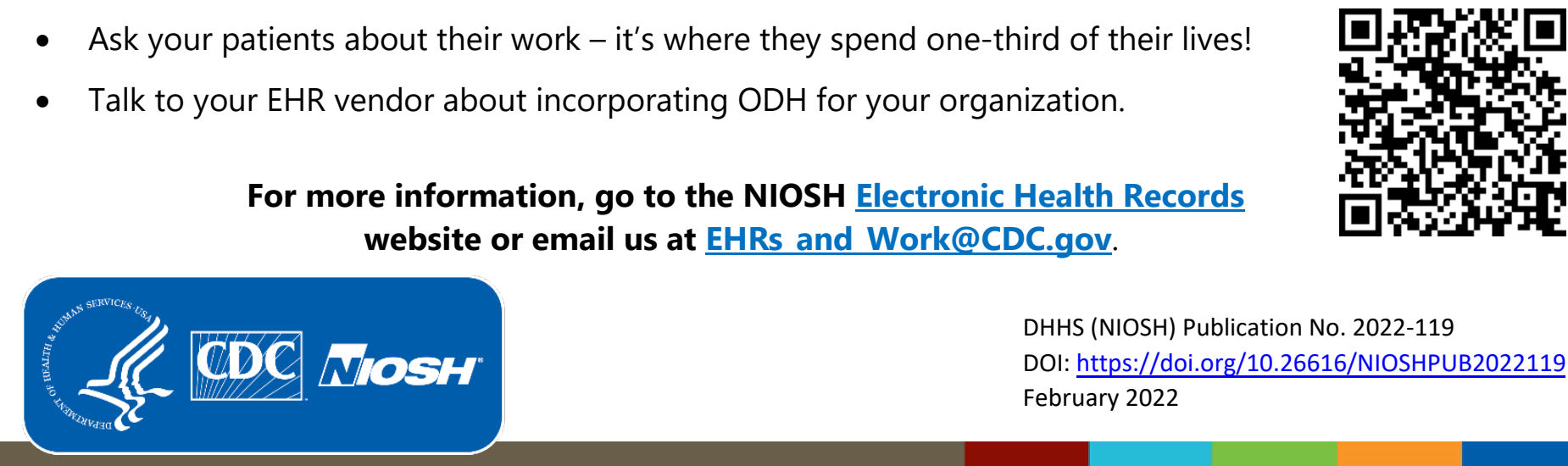